\title{
Golgi Protein 73 as a Diagnostic Tool for Hepatocellular Carcinoma in Cirrhotic Hepatitis C Patients
}

\author{
Basma Badreldin Hasan ${ }^{1}$, Ahmed Gaber ${ }^{2}$, Seham A. Omar ${ }^{3}$ \\ ${ }^{1}$ Department of Clinical Pathology, Faculty of Medicine, Port said University, Egypt \\ ${ }^{2}$ Department of Endemic and Infectious Diseases, Faculty of Medicine, Suez Canal \\ University, Egypt. \\ ${ }^{3}$ Department of Internal Medicine, Faculty of Medicine, Suez Canal University, Egypt.
}

Corresponding Author Basma Badreldin Hasan

Mobile: $+201001593877$

E mail:

basmabdr@yahoo.com

Key words: Hepatocellular carcinoma, hepatitis $C$ virus, liver cirrhosis, serum GP73, Alphafetoprotein
Background and study aim: Hepatocellular carcinoma (HCC) is the commonest primary liver cancer originating from the hepatocytes. HCC nowadays considered the $3^{\text {rd }}$ cause of malignancy related mortality allover the world. Small HCC, means that size of hepatic focal lesions did not exceed 5 centimeters in patients with solitary hepatoma, typically have no clinical manifestations. This makes cirrhotic liver patients a perfect target population for HCC surveillance. This study was designed to evaluate the clinical use of serum GP73 levels as a good diagnostic biomarkers for malignant liver tumours in cirrhotic patients due to HCV infection.

Subjects and Methods: The study was designed as a Descriptive - Analytic study at Suez Canal University Hospital. The study included 87 individuals who were divided into four groups (healthy, chronic hepatitis, cirrhosis and HCC patients). All patients were clinically evaluated, had routine laboratory investigations and measurements of circulating levels of AFP and GP73. Abdominal

\section{INTRODUCTION}

Chronic hepatitis $\mathrm{C}$ infection leads to liver cirrhosis and then complicated by hepatocellular carcinoma (HCC). HCC accounts for more than $90 \%$ of primary hepatic malignancy and is serious complication of liver diseases all over the world [1]. The burden of chronic disease is anticipated to rise as a result of increasing rates of hepatitis $\mathrm{B}$ and $\mathrm{C}$ prevalence, alcoholism, and obesity-related liver disease, it's expected that the incidence of $\mathrm{HCC}$ will increase in the foreseeable future [2]. ultrasonography and Triphasic CT abdomen was done for detection of hepatic focal lesions and hepatobiliary system.

Results: The maximum cutoff levels for GP73 was $534.5 \mathrm{ng} / \mathrm{L}$ and in comparison the cutoff AFP level was $32 \mathrm{ng} / \mathrm{mL}$. For GP73, the sensitivity was $88 \%$ and specificity $88 \%$ while the sensitivity of AFP was $72 \%$ and the specificity of AFP was $80 \%$. The $+\mathrm{v}$ predictive value of GP73 and the -ve predictive value of GP73 were $84.6 \%$ and $87.5 \%$ while the same values of AFP were $75 \%$ and $73.1 \%$, respectively.

Conclusion: It was found that serum GP73 was up-regulated in HCC and we can use it as a good biomarker for early detection and for screening of malignant liver lesions in cirrhotic patients due chronic HCV infection and it would be more accurate and effective tool than serum AFP in discriminating the malignant liver lesion from the chronic hepatitis.
The best way to put the treatment policies (therapy guidance) is the early screening of cirrhotic patients for HCC and early detection for recurrence risk and prognosis [3]. Alpha-fetoprotein (AFP) is considered the commonest serological biomarker which is used for detection, diagnosis and prognosis of malignant hepatic focal lesions [4,5]. Because of low sensitivity and specificity of AFP decreasing its diagnostic accuracy and the European Association for the Study of the Liver (EASL) did not recommend AFP as diagnostic marker of HCC. Nowadays we are using 
Serum $\alpha$-fetoprotein (AFP) in addition to ultrasound of the liver every 4-6month intervals for screening of hepatocellular carcinoma in patients with cirrhosis $[6,7]$.

Several studies showed different tumor markers for HCC screening as AFP-L3, descarboxyprothrombin (DCP), hepatoma-specific glutamyl transferase (HS-GGT), human cervical cancer oncogene (HCCR), B-cell lymphoma (Bcl-2), heat shock protein (HSP), vascular endothelial growth factor (VEGF), interleukin-8 (IL-8), angiopoietins, matrix metalloproteinases and telomerase. They considered it to be promising tumor markers for $\mathrm{HCC}$ screening and prognosis in patients with advanced liver cirrhosis [4]. After rapid progression in understanding the pathogenesis of liver cancers, there is urgent need for various tumor markers and molecular biomarkers for their screening power and prognostic significance in terms of angiogenesis, invasion, and metastasis in patients with HCC [5]. Furthermore, new HCC-specific biomarkers in the coming days will appear after proteomics analysis [6].

Golgi protein 73 (GP73) is a Golgi transmembrane glycoprotein [7]. In healthy liver, GP73 is primarily expressed in biliary epithelial cells but rarely in hepatocytes, while increased GP73 expression in hepatocytes appears in advanced liver disease regardless the etiology [8]. Golgi protein 73 (GP73) has been suggested as a serum marker for the diagnosis of hepatocellular carcinoma (HCC). However, this has been challenged in recent years. In most of studies, serum GP73 is increased in HCC patients with cirrhosis but not in those without cirrhosis [9].

That's why it was important to try to assess the efficacy of using of serum GP73 levels as a good diagnostic biomarkers for early detection of malignant liver tumours in cirrhotic patients due to $\mathrm{HCV}$ infection..

\section{PATIENTS AND METHODS}

The study was carried out as a DescriptiveAnalytic study. The study was conducted in Suez Canal university hospitals (gastroenterology and Hepatology unit) after obtaining an informed consent and the protocol was approved by faculty of medicine review board and ethical committee and Lab work was performed at the Clinical Pathology Department of Suez Canal
University Hospital. The study sample was 87 individuals and was classified into four groups:Group 1:- 12 healthy individuals (normal liver profile and normal U/S), Group 2:- 25 chronic hepatitis $\mathrm{C}$ patients (Diagnosis of chronic hepatitis was based on normal liver functions and abdominal ultrasound, and +ve HCVAb\& PCR), Group 3: - 25 patients with liver cirrhosis due to HCV infection (Diagnosis of cirrhosis was based on combined historical, clinical, laboratory and radiological findings) and Group 4:- 25 patients with HCV-related HCC (HCC was diagnosed on the basis of the presence of typical vascular enhancement pattern of liver lesion (s) in contrast enhanced dynamic CT scan or MRI). Patients were excluded from the study if they had any other malignant processes or have been receiving treatment for hepatitis $\mathrm{C}$ or hepatocellular carcinoma at the time of inclusion and also we exclude patients with hepatitis B infection.

\section{Investigations:}

All subjects were clinically evaluated, had laboratory investigations; blood samples were collected in the clinic from the 4 groups. About $10 \mathrm{~cm}$ were collected from each patient for:

1. Hematological assessment: Complete Blood Count (CBC) was carried out using automated cell counters (CELL- DYN 1700).

2. Prothrombin time, activity and INR was assessed.

3. Biochemical assessment: tests for hepatic function (SGOT, SGPT, serum albumin, serum bilirubin) were carried out using (Cobas HITACHI 912 automatic analyzer (Roche Diagnostics GmbH. Sandhofer Str. Mannheim, D-68298 Germany).

4. Serological assessment:

- Serum HCV antibody: qualitative assessment of hepatitis $\mathrm{C}$ virus antibodies (anti-HCV) have been done by using anti$\mathrm{HCV}$ enzyme immunoassay kit for in human serum or plasma samples (Walker, 1999). We used ELISA kits supplied by Diasorin S.p.A. 13040 Saluggia (VERCELLI) - ITALY.

- Serum HBsAg: hepatitis B surface antigen (HBsAg) was detected by using HBsAg enzyme immunoassay kit and for qualitative assessment in human serum or plasma samples (Hoofnagle, 1999 using ELISA kits supplied by Diasorin S.p.A. 13040 Saluggia (VERCELLI) - ITALY). 
- Alpha fetoprotein (AFP) was assessed by using Biomerieux Vidas Automated Immunoassay Analyzer. Normal level of $\mathrm{AFP}=5-15 \mathrm{ng} / \mathrm{L}$

- Serum Golgi Protein 73(GP73) levels were determined by a quantitative sandwich enzyme immunoassay technique using a commercially available kit (Glory Science Co., Ltd, China) .The kit is for quantitative level of GP-73 in the sample, adopt purified Human GP-73 to coat microtitre plate, make solid phase antibody, then add GP-73 to wells. Combine GP-73 antibody with labeled HRP to form antibody- antigen- enzymeantibody complex, after washing completely, add TMB substrate solution. TMB substrate solution becomes blue color at HRP enzymecatalyzed, reaction is terminated by the addition of a stop solution and the color change is measured at a wavelength $450 \mathrm{~nm}$. The concentration of GP-73 in the sample is then determined by comparing the O.D. of the samples to the standard curve. Detection range of the kit is: $50 \mathrm{ng} / \mathrm{L}-500 \mathrm{ng} / \mathrm{L}$. which is the normal level of GP73

5. Abdominal U/S to rule out hepatic focal lesion(s) and Triphasic CT for diagnosis of HCC.

\section{Statistical analysis}

SPSS, version 21 for windows (Inc, Chicago, IL, USA) was used for all statistical analyses. Qualitative data were presented as frequency and percentage. Chi square and Fisher's exact tests were used to compare groups. Quantitative data were presented as mean and standard deviation. For non- parametric data, student test and MannWhitney U test were used to compare level difference of sGP73 between two groups while ANOVA and Kruskal Wallis were used to compare level difference of sGP73 between more than two groups. Receiver operator characteristic (ROC) curve analysis was used to generate sensitivity and specificity at different cutoffs. The best cutoff was set at the value where sensitivity and specificity were maximal. Correlation between serum level of sGP73 and laboratory parameters was assessed by Spearman's correlation coefficient. The statistical significance was set at $\mathrm{P}$-value of less than 0.05 for all tests. The abnormal data were tested by parametric tests.

\section{RESULTS}

\section{Demographic data}

The study included 87 individuals of both sexes; 28 females (representing 32.2\%) and 59 males (representing 67.8\%). The mean value of their ages was $(46 \pm 6.5)$, ranged between 34 to 64 years.

\section{Laboratory Tests: 1. Alpha-fetoprotein (AFP):}

AFP level was statistically significant difference between; healthy individuals group $(1.7 \pm 0.4$ $\mathrm{ng} / \mathrm{mL}$ ), chronic hepatitis $\mathrm{C}$ patients group $(2.4 \pm 1.2 \mathrm{ng} / \mathrm{mL})$, patients with HCV-related liver cirrhosis $(11.9 \pm 13.2 \mathrm{ng} / \mathrm{mL})$ and HCC patients group $(622.6 \pm 555.4 \mathrm{ng} / \mathrm{mL})(\mathrm{P}<0.001)($ Table 1$)$, (Figure 1).

\section{Golgi Protein 73 level among the four studied groups:}

There was a statistically significant difference in GP-73 levels between; healthy individuals group $(451.1 \pm 20.9 \mathrm{ng} / \mathrm{L})$, chronic hepatitis $\mathrm{C}$ patients group $(493.9 \pm 29 \mathrm{ng} / \mathrm{L})$, patients with $\mathrm{HCV}$ related liver cirrhosis $(497.6 \pm 33 \mathrm{ng} / \mathrm{L})$ and $\mathrm{HCC}$ patients group $(543.9 \pm 20 \mathrm{ng} / \mathrm{L})(\mathrm{P}<0.001)$ (Table 1) (Figure 2).

\section{Correlation between Golgi Protein 73 level and other parameters in the studied groups:}

There was a negative correlation between GP-73 and hemoglobin in HCC group because with increasing the degree of cirrhosis, decreasing the level of $\mathrm{Hb}$ and increasing the risk of HCC.As we know there are many causes of anaemia in advanced cirrhosis as hypersplenism, portal hypertension (bleeding O.V. or piles), and bone depression by $\mathrm{HCV}$ infection. In chronic $\mathrm{HCV}$ group, there was a correlation between serum GP-73 and AST. There was a positive correlation between serum GP-73 and ALT, AST and total bilirubin in cirrhotic and HCC group. Also, there was a -ve correlation between serum GP-73 and albumin in cirrhotic and HCC group (Table 2,3) (Figure 3,4).

4. Cutoff values for GP73 and AFP in discriminating malignant tumours from liver cirrhosis: 
The best cutoff levels for serum GP73 and serum AFP were $534.5 \mathrm{ng} / \mathrm{L}$ and $32 \mathrm{ng} / \mathrm{mL}$, respectively. The sensitivity of GP73 and AFP were $88 \%$ and $72 \%$ respectively while the specificity for GP73 and AFP were $88 \%$ and $80 \%$ respectively. The + predictive value (PPV) of GP73 and AFP were $84.6 \% \& 75 \%$ respectively. While -ve predictive value (NPV) of GP73 and AFP were 87.5\% $\& 73.1 \%$ respectively. The area under the curve (AUC) for GP73 was 0.924 (S.E. $=0.0387$, $95 \% \mathrm{CI}=0.848-1.000)$ compared with 0.764 (S.E. $=0.0725,95 \% \mathrm{CI}=0.622-0.906$ ) for AFP ( $\mathrm{P}=0.049)$. So GP73 is superior to AFP in HCC screening.

Table (1): Alfa fetoprotein and GP73 among studied groups.

\begin{tabular}{|c|c|c|c|c|c|c|c|}
\hline & & $\begin{array}{r}\text { Group1 } \\
(n=12)\end{array}$ & $\begin{array}{c}\text { Group2 } \\
(n=25)\end{array}$ & $\begin{array}{c}\text { Group3 } \\
(n=25)\end{array}$ & $\begin{array}{c}\text { Group4 } \\
(\mathrm{n}=25)\end{array}$ & $\mathbf{F}$ & p-value \\
\hline \multirow{2}{*}{$\begin{array}{c}\text { AFP } \\
(\mathrm{ng} / \mathrm{mL})\end{array}$} & Mean \pm SD & $1.7 \pm 0.4$ & $2.4 \pm 1.2$ & $25 \pm 22.4$ & $340 \pm 443.3$ & \multirow{2}{*}{11.3} & \multirow{2}{*}{$<0.001$} \\
\hline & Range & $1-2.4$ & $1-5.2$ & $3-84$ & $5-1000$ & & \\
\hline \multirow{2}{*}{$\begin{array}{l}\text { GP73 } \\
\text { (ng/L) }\end{array}$} & Mean \pm SD & $451.1 \pm 20.9$ & $493.9 \pm 29$ & $497.6 \pm 33$ & $543.9 \pm 20$ & \multirow{2}{*}{35} & \multirow{2}{*}{$<0.001$} \\
\hline & Range & $409.5-474.8$ & $428.7-536.4$ & $409.5-542.2$ & $474.8-575.1$ & & \\
\hline
\end{tabular}

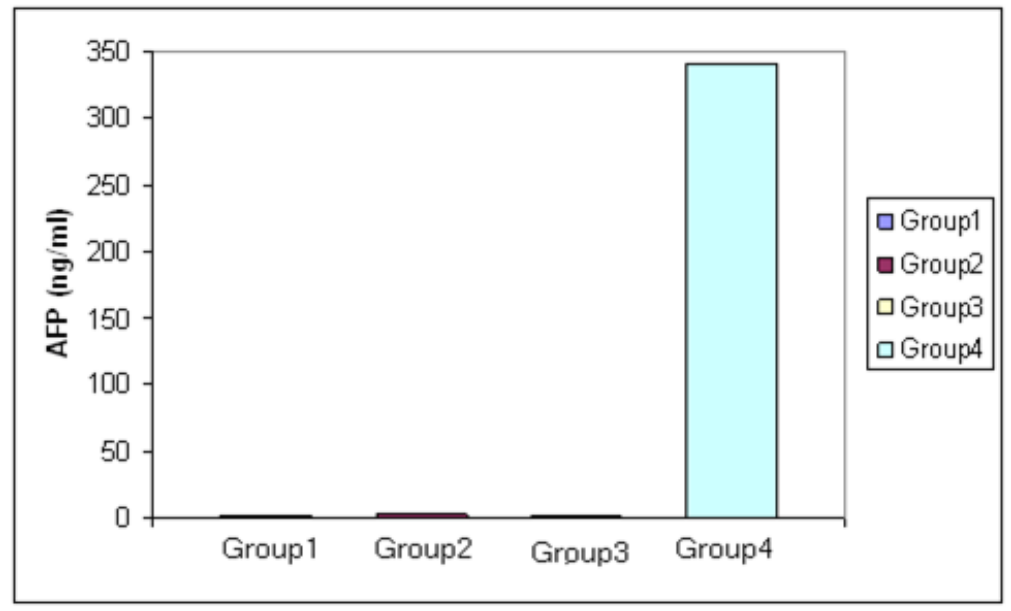

Figure (1): Serum AFP in group 1, group 2, group 3 and group 4 .

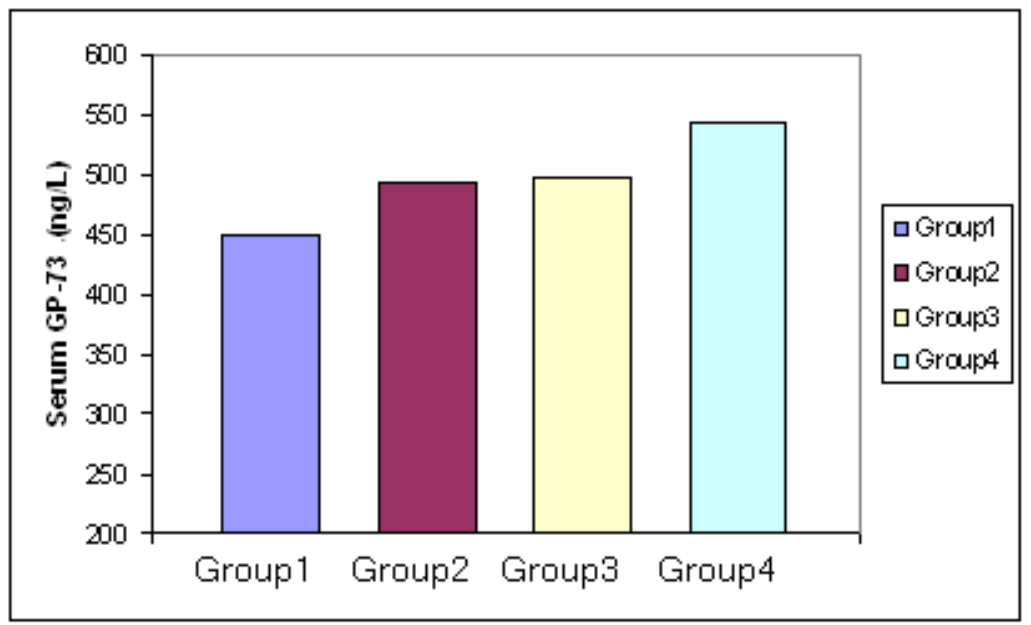

Figure (2): Serum GP-73 in group 1, group 2, group 3 and group 4. 
Table (2): Correlation between GP-73 and other parameters in healthy group.

\begin{tabular}{|l|c|c|}
\hline \multirow{2}{*}{ Variables } & \multicolumn{2}{|c|}{ GP-73 } \\
\cline { 2 - 3 } \multicolumn{1}{|c|}{} & $\mathbf{r}$ & p-value \\
\hline INR & -0.1 & 0.4 \\
\hline Hb & 0.5 & 0.049 \\
\hline Platelet & -0.3 & 0.2 \\
\hline Albumin & 0.1 & 0.4 \\
\hline Total bilirubin & 0.3 & 0.2 \\
\hline ALT & -0.1 & 0.4 \\
\hline AST & -0.1 & 0.4 \\
\hline AFP & 0.4 & 0.09 \\
\hline
\end{tabular}

$\mathrm{P}$-value $<0.05$ is significant

Table (3): Correlation between GP-73 and other parameters in HCC group.

\begin{tabular}{|l|c|c|}
\hline \multirow{2}{*}{ Variables } & \multicolumn{2}{|c|}{ GP-73 } \\
\cline { 2 - 3 } & r & p-value \\
\hline INR & -0.02 & 0.5 \\
\hline Hb & -0.3 & 0.07 \\
\hline Platelet & -0.02 & 0.5 \\
\hline Albumin & -0.4 & 0.02 \\
\hline Total bilirubin & 0.5 & 0.005 \\
\hline ALT & 0.4 & 0.02 \\
\hline AST & 0.4 & 0.02 \\
\hline AFP & 0.2 & 0.3 \\
\hline
\end{tabular}

$\mathrm{P}$-value $<0.05$ is significant

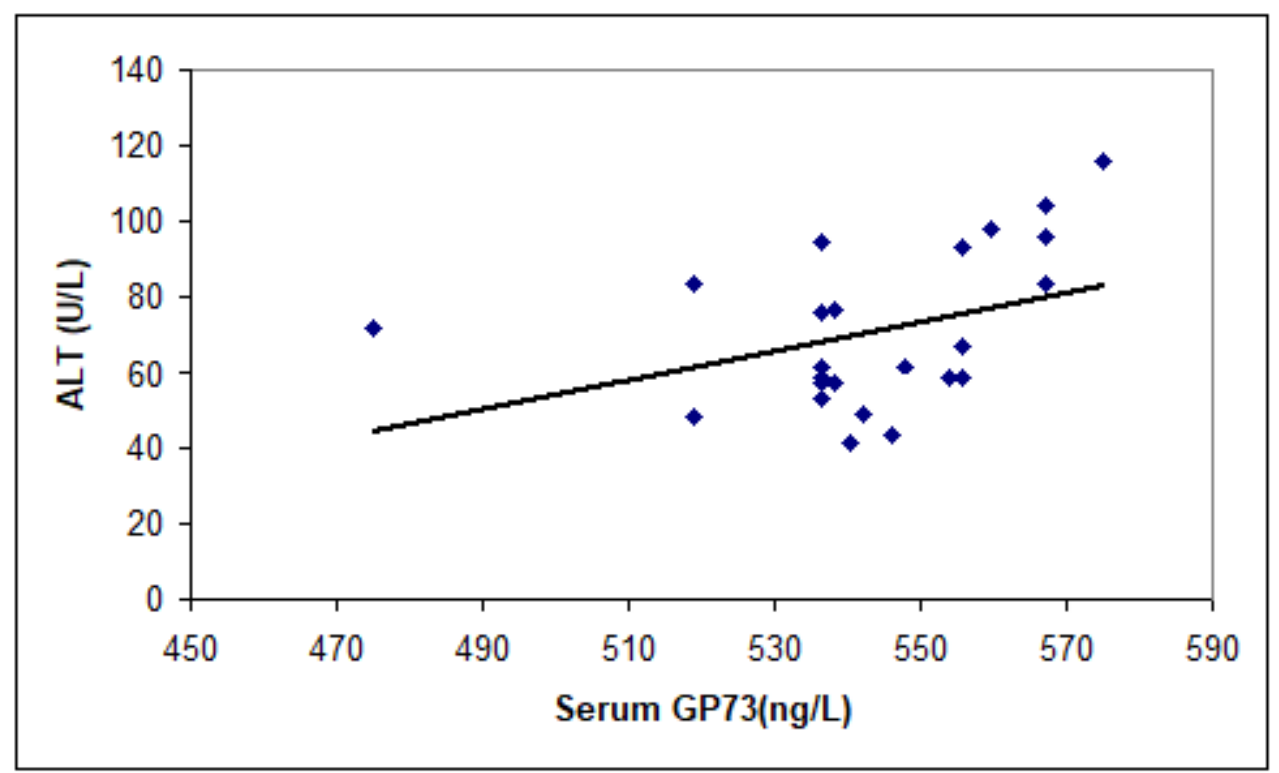

Figure (3): Correlation between ALT and GP-73 in HCC group. 


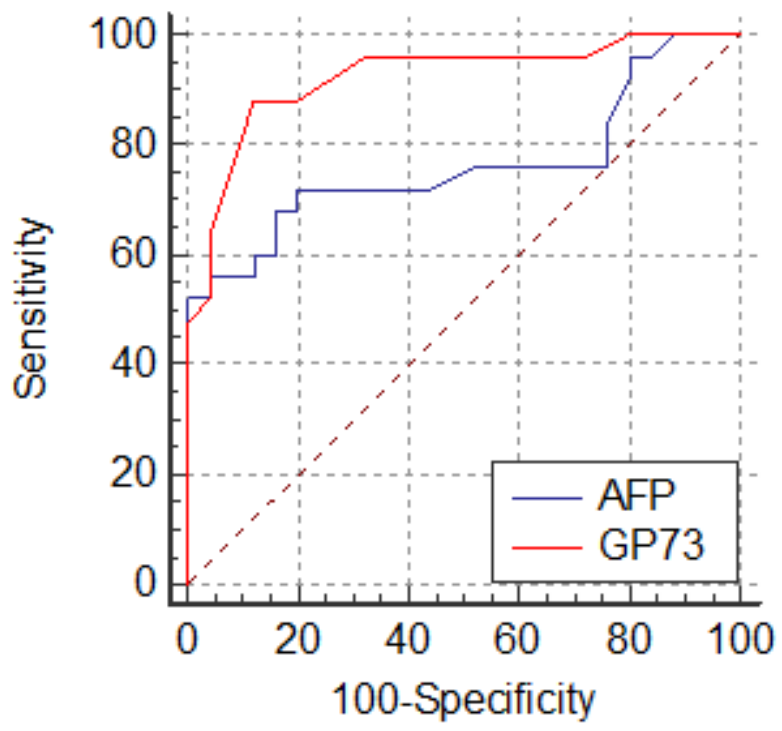

Figure (4): ROC Curve of serum GP73 and AFP in detection of HCV patients with HCC among HCV patients with cirrhosis.

\section{DISCUSSION}

Cirrhosis is the main risk factor for developing HCC, which hepatitis C \& B and infection are its major causes. Indeed, evidence shows that $\mathrm{HCV}$ infection was responsible for $25 \%$ of all patients of malignant liver tumours HCC worldwide [8]. The hepatologists were facing many difficulties in diagnosis and early detection of HCC, especially in cirrhotic patients depending on the appearance of small hepatic nodules. Usually, small HCC has no distinct clinical features. That is why cirrhotic patients are an ideal target population for HCC screening [9].

Many studies observed marked elevation of serum GP73 levels which detected in liver diseases with different causes as infectious causes (HBV, HCV) or non-infectious causes (alcohol-induced liver disease, autoimmune hepatitis). So, some researchers concluded that this rise in the GP73 expression is a response of hepatocyte to a variety of disease etiologies [10].

Men constituted a higher percentage of cases in the HCC group (80\%). Same results were described by Nafee et al.[11]who found that men and women constituted (80\% and $20 \%$, respectively) of cases in the $\mathrm{HCC}$ group. It was reported that $\mathrm{HCC}$ is more common in men than women by three times, which could be because men are more exposed to risk factors than women [12].

In our work, we found that the mean of serum AFP level was elevated and it was highly statistical significance difference $(\mathrm{p}<0.001)$ in HCC group $(340 \pm \mathrm{ng} / \mathrm{ml})$ when compared with healthy control group $(1.7 \pm$ $\mathrm{ng} / \mathrm{ml}$ ), chronic HCV patients group (2.4 \pm $\mathrm{ng} / \mathrm{ml})$ and cirrhotic group $(25 \mathrm{ng} / \mathrm{ml})$. This was in agreement with Awadallah and his colleagues [13] in 2011 who found that the elevation in AFP in HCC group was highly statistical significance difference $(\mathrm{p}<0.01)$. The median serum AFP in HCC group was $26.5 \mathrm{ng} / \mathrm{ml}$ when compared to the cirrhotic group was $5.35 \mathrm{ng} / \mathrm{ml}$

The levels of serum GP73 were statistically different between healthy, chronic hepatitis $\mathrm{C}$ patients, liver cirrhosis patients and HCC patients (the mean levels of GP73 were $451.1 \pm \mathrm{ng} / \mathrm{L}, 493.9 \pm \mathrm{ng} / \mathrm{L}, 497.6 \pm \mathrm{ng} / \mathrm{L}$ and $543.9 \pm \mathrm{ng} / \mathrm{L}$ respectively, $(\mathrm{p}<0.001)$. this means the serum GP73 levels were increased in HCC patients more than in those control, chronic hepatitis $\mathrm{C}$ patients and liver cirrhosis patients. 
These data are in accordance with findings observed by Yao et al in 2016 who reported that serum GP73 levels were significantly increased in HCC patients due to hepatitis C virus infection in comparison with cirrhotic controls [14]. Also, Mao et al in 2010 determined that GP73 may be helpful in early detection of HCC recurrence in postoperative patients[15].

Concerning the correlation, there was a positive correlation between serum GP-73 and ALT, AST and total bilirubin in cirrhotic and HCC group. Also, there was a negative correlation between serum GP-73 and albumin in cirrhotic and HCC group. The same results were obtained by Tian and his colleagues who explained that as elevated ALT is a result of early damage at a subcellular level, and AST reflects further mitochondrial or nuclear damage[16].

In this result, AFP sensitivity and specificity for HCC diagnosis were $72 \%$ and $80 \%$, respectively, at a cutoff value of $32 \mathrm{ng} / \mathrm{ml}$. This result agreed with Khalil et al. [9] who found that AFP with a cut off value $20 \mathrm{ng} / \mathrm{ml}$ has low sensitivity and high specificity. However, AFP level of $20 \mathrm{ng} / \mathrm{ml}$ is mostly used as upper limit of normal; more patients with chronic liver disease, especially those with a high level of hepatocyte regeneration, can show elevated serum AFP in the absence of malignancy.

This current data also showed that sensitivity and specificity of serum GP73 in the differentiation of $\mathrm{HCC}$ patients from cirrhotic patients were $88 \%$ and $88 \%$ respectively using a cut off value of 534.5 $\mathrm{ng} / \mathrm{L}$. Analyzing of AUC showed that serum GP73 had greater AUC (0.924) than that of AFP (0.764) which suggests that serum GP73 level might be superior to AFP in the diagnosis of HCC and differentiating it from cirrhosis.

An important aspect of screening marker is whether it is highly sensitive and specific to the target tumor. Serum AFP level sometimes increases in patients with liver cirrhosis, and thus false positive is a problem in using AFP as a marker for HCC. It has been reported that approximately $50 \%$ of liver cirrhosis patients have increased serum AFP value [17].

\section{CONCLUSION}

It was found that serum GP73 was up-regulated in HCC and we can use it as a good biomarker for early detection and for screening of malignant liver lesions in cirrhotic patients due to chronic $\mathrm{HCV}$ infection and it would be more accurate and effective tool than serum AFP in discriminating the malignant liver lesion from the chronic hepatitis.

Funding: This research did not receive any specific grant from funding agencies in the public, commercial, or not-for-profit sectors.

Conflict of interest: Authors declare no conflict of interest.

\section{Ethical Approval:}

All participants was informed written consent for participation in the study that was approved by the committee of medical ethics- Faculty of Medicine-Suze Canal University.

\section{REFERENCES}

1. Liu T, Yao M, Liu S, Wang L, Wang L, Huo J, et al. Serum Golgi protein 73 is not a suitable diagnostic marker for hepatocellular carcinoma. Oncotarget 2017; 8(10): 16498-16506.

2. Fujiwara N, Friedman SL, Goossens N, Hoshida Y. Risk factors and prevention of hepatocellular carcinoma in the era of precision medicine. $\mathrm{J}$ Hepatol 2018; 68(3):526-49.

3. El-Serag HB, Davila JA. Surveillance for hepatocellular carcinoma: in whom and how? Therap Adv Gastroenterol 2011; 4(1):5-10.

4. Tsuchiya N, Sawada Y, Endo I, Saito K, Uemura Y, Nakatsura T. Biomarkers for the early diagnosis of hepatocellular carcinoma. World $J$ Gastroenterol 2015; 21(37):10573-83.

5. Berretta M, Cavaliere C, Alessandrini L, Stanzione B, Facchini G, Balestreri L, et al. Serum and tissue markers in hepatocellular carcinoma and cholangiocarcinoma: clinical and prognostic implications. Oncotarget [Internet]. 2017; 8(8):14192-220. 
6. Kimhofer T, Fye H, Taylor-Robinson S, Thursz M, Holmes E. Proteomic and metabonomic biomarkers for hepatocellular carcinoma: a comprehensive review. $\mathrm{Br} J$ Cancer 2015; 112(7):1141-56.

7. Cao FF, Yu S, Jiang ZY, Bao YX. Diagnostic accuracy of Golgi protein 73 in primary hepatic carcinoma using ELISA: a systematic review and meta-analysis. Clin Lab 2014; 60:587-597.

8. Xu Z, Liu L, Pan X, Wei K, Wei M, Liu L et al. Serum Golgi Protein 73 (GP73) is a diagnostic and prognostic marker of chronic HBV liver disease. Medicine 2015; 94:e659.

9. Khalil FM, Negm SI, El Assal MA, Yousif AA, Salem RS. Serum level of Golgi protein-73 as a diagnostic marker for hepatocellular carcinoma. Benha Medical Journal 2018, 35:36-41.

10. Mariam A, Emad F, Dalia WF, Elela HA, Abdelsalam $\mathrm{OH}$. Golgi protein 73 versus alpha fetoprotein as a marker for hepatocellular carcinoma. Medicine (Baltimore) 2015; 94:e659.

11. Nafee AM, Pasha HF, El Aal SMA, Mostafa NA. Clinical significance of serum clusterin as a biomarker for evaluating diagnosis and metastasis potential of viral-related hepatocellular carcinoma. Clin Biochem 2012; 45(13-14):1070-4.
12. Sherlock S, Dooley J. Diseases of the liver and biliary system. Wiley Online Library; 2002.

13. Awadallah AM, Issa HA, Soliman MS. Evaluation of serum chromogranin a as a useful tumor marker for diagnosis of hepatocellular carcinoma. J Am Sci 2011; 7(1):999-1007.

14. Yao M, Zhao J, Lu F. Alpha-fetoprotein still is a valuable diagnostic and prognosis predicting biomarker in hepatitis B virus infection-related hepatocellular carcinoma. Oncotarget 2016; 7:3702-8. doi: 10.18632/oncotarget.6913.

15. Mao Y, Yang H, Xu H, Lu X, Sang X, Du S, et al. Golgi protein 73 (GOLPH2) is a valuable serum marker for hepatocellular carcinoma. Gut 2010; 59(12):1687-93.

16. Tian L, Wang Y, Xu D, Gui J, Jia X, Tong H, et al. Serological AFP/Golgi protein 73 could be a new diagnostic parameter of hepatic diseases. Int J Cancer 2011; 129(8):1923-31.

17. AlSalloom AAM. An update of biochemical markers of hepatocellular carcinoma. Int $J$ Health Sci (Qassim) 2016; 10(1):121-36. 